\title{
ARTEFATOS MIDIÁTICOS PARA A INFÂNCIA E A LINGUAGEM CARTOGRÁFICA
}

Jaira Maria da Silva de Almeida ${ }^{1}$

jaira1986@gmail.com

Astrogildo Fernandes da Silva Júnior ${ }^{2}$

silvajunior_af@yahoo.com.br

Resumo: Este trabalho apresenta resultados de uma dissertação desenvolvida no Programa de Pós Graduação em Educação da Universidade Federal de Uberlândia (PPGED/UFU). O objetivo geral consistiu em analisar as potencialidades das produções cartográficas presentes em revistas veiculadas para o público infantil para o processo de ensino e aprendizagem da cartografia. A metodologia recorreu a pesquisa bibliográfica e documental. Nessa apresentação o recorte é as relações que se estabelecem entre cartografia, infância e mídia. Constata-se que as crianças, na contemporaneidade se constituem em mercado consumidor, assim são inúmeros os produtos da mídia que adentram esse universo. A revista se apresenta como um desses produtos e traz produções cartográficas em que a dimensão informativacomunicativa e expressiva estão em ação. É no embate constante da relação texto, produção e público que os significados são construídos, às crianças, não cabe apenas o papel passivo de fruidores de um mercado cultural, mas se constituem também como produtores de cultura. Os produtores da mídia recorrem às produções cartográficas para finalidades variadas; no caso das revistas seja para ilustrar ou para comunicar alguma informação. Compreender como e quais relações se estabelecem entre essas criações midiáticas e a infância conduz à formação de um olhar crítico e aponta para os limites e possibilidades de atuação de ambas as partes na construção da realidade vivenciada. Muitas são as produções cartográficas presentes nesses dispositivos, e percebemos que este, ao ser abordado no espaço escolar, não apenas contribui para o processo de ensino e aprendizagem da cartografia, como finda por promover uma educação para as mídias com a proposição do desenvolvimento de uma postura questionadora frente a esses artefatos. 


\section{Introdução}

Abordamos neste artigo, a linguagem cartográfica presente em artefatos midiáticos voltados para a infância. Analisamos como a mídia atua para a formação de seu mercado consumidor, de quais perspectivas utiliza para direcionar a construção de seus produtos, concomitantemente buscando moldar/formatar seu público.

Os produtos da mídia recorrem às produções cartográficas para finalidades variadas; seja para ilustrar ou para comunicar alguma informação. Assim, discorremos sobre a linguagem cartográfica, artefatos midiáticos e infância, especificamente sobre a importância de uma educação para as mídias que não se paute apenas no seu uso instrumental, mas nestas como formas de cultura e comunicação, como maneiras de pensar e representar o mundo. Da mesma maneira, abordamos aspectos da linguagem cartográfica, presente em artefatos midiáticos, a sua dimensão informativa e comunicativa assim como expressiva.

\section{Artefatos midiáticos e a infância}

Para além da escola, as crianças vivenciam outros ambientes e objetos que numa complexa interação geram realidades/espaços diversos. A constatação de um cotidiano na infância, cada vez mais saturado de mídia é visível, e ocorre em distintos espaços que a criança percorre/habita ao longo de sua infância.

\footnotetext{
'Mestre em Educação pelo Programa de Pós-Graduação em Educação da Universidade Federal de Uberlândia - PPGED/UFU. E-mail: jaira1986@gmail.com

${ }^{2}$ Doutor em Educação pelo Programa de Pós-Graduação em Educação da Universidade Federal de Uberlândia - PPGED/UFU. Professor do Curso de História da FACIP/UFU e do PPGED/UFU. E-mail: silvajunior_af@yahoo.com.br
}

Essa relação está inserida num determinado contexto social, a saber, o de uma sociedade capitalista baseada em relações econômicas. A atuação da criança no campo do consumo chama a atenção: a criança aparece como mercado consumidor assumindo um destaque considerável nas mídias, sendo usuária das tecnologias e cada vez mais surgem produtos midiáticos para a infância. Assim, evidencia-se a existência de todo um mercado voltado para a produção de produtos para as crianças. Ademais, a exploração desse mercado funciona também como uma ponte para se chegar ao mercado dos adultos, conforme Buckingham (2012, p. 45): 
nos últimos anos as crianças têm se tornado cada vez mais importante não apenas como um mercado em si, mas também como um meio de se alcançar os mercados dos adultos. Os mercadólogos estão visando mais diretamente às crianças, cada vez mais jovens, e estão usando uma gama bem mais ampla de técnicas que vão além da propaganda convencional.

Para compreender a criança e o consumo no interior do contexto sócio-histórico contemporâneo, devemos considerar que hoje as crianças vivenciam a sociedade do consumo numa dinâmica em que a sua existência está imersa num ciclo a perambular e se reinventar na medida em que ela é construída. Assim, é preciso considerar que esses caminhos são também significados pelas crianças, contrariando a ideia de que todo o poder de constituição desse processo esteja nas mãos dos que pensam a mídia e o consumo. Diante disso, as respostas de uma abordagem tradicional, com base numa psicologia desenvolvimentista, não conseguem mais abarcar os questionamentos e desafios que surgem com as novas problematizações estabelecidas dentro da relação criança e consumo.

Um debate polarizado sobre a relação criança-consumo deixa de pensar em importantes questões relacionadas a essa problemática, simplificando a questão, o que significa pensar a partir de uma visão reducionista, que não permite que se veja além do que está posto. Contudo, ir além das oposições binárias e caminhar na direção de um pensamento mais complexo sobre as práticas de consumo em que as crianças estão imersas se faz necessário no cenário atual.

Os estudos que procuram ir além de um dualismo indicam que as crianças, ao terem contato com textos, ativamente produzem significado, mas os textos trazem consigo restrições ideológicas e formais que agem limitando certos entendimentos em detrimento de outros. Os textos não são entidades independentes, nascem em contextos sociais que atuam no processo de sua produção, leitura e recepção pelo público.

Estudos realizados por Buckingham (2012) indicam que os produtores de mídia para crianças estão imersos numa complexa relação em que não se define totalmente os significados que seus produtos irão ter, e o público ao qual o produto se dirige também não age livre na criação de significados. Os significados construídos se produzem no embate constante da relação texto, produção e público em que nenhum ponto é determinante. O público é ativo, mas assim como a mídia, atua sobre 
determinadas condições sociais; as crianças, especificamente, são restringidas por instituições sociais e discursos que interpelam a sociedade em geral.

Os responsáveis pelo mercado lançam mão de técnicas de marketing para a captura de seus consumidores. Existe uma profusão de discursos que lidam com distintas ideias de crianças. Podemos considerar que esses discursos constroem ideias de consumidor com as quais querem lidar. Segundo Buckingham (2012, p. 56), "ao invés de adotar técnicas agressivas de venda (hard sell), os mercadólogos precisam cada vez mais levar em conta o ceticismo e a possível resistência dos consumidores". Mudanças que visualizamos no mercado que nos parecem "novas" técnicas para atingir esse público, de acordo com Buckingham (2012), ainda que nos pareçam novas, estão pautadas pela visão positivista e de estudos da psicologia tradicional, retratando apenas as novas formas de se construir a criança que consome, mas ainda sob uma perspectiva tradicionalista.

Uma construção possível é a dos meios populares de debate que fala de uma criança inocente, indefesa e incapaz de resistir ao poder da mídia. Nessas discussões raramente se encontra presente a voz das crianças ou ao menos a tentativa de considerar suas perspectivas. Outro discurso possível é o que delega às crianças um falso poder, no qual elas saberiam o que querem exatamente, seriam conhecedoras dos produtos e teriam gostos definidos. No entanto, a mídia e o mercado, para darem existência a esse "poder", vigiam e usam de artimanhas para descobrir e entender as perspectivas desses sujeitos, para ter acesso aos seus gostos e percepções e, então, agir.

As mídias tentam navegar a partir da perspectiva das crianças, objetivando adentrar o universo infantil para, finalmente, atingirem seus objetivos. A partir do discurso de que querem escutar "a voz das crianças" e considerar seus desejos, não respeitam o espaço delas, estabelecendo uma relação de invasão e colonização. Mas, como citado, existe uma contra-ação por parte do público que não se constitui em receptor passivo dos produtores de mídias.

Percebemos, então, que existe uma profusão de discursos sobre a criança que vão ao encontro dos interesses de quem os cria. Em face disso, se faz necessário ponderar sobre o uso da mídia. Os estudos sobre esses meios precisam ultrapassar 
uma concepção que finda por destacar seu uso funcional e instrumental. Sob essa demanda Buckingham (2008, p.03) ressalta a necessidade de um alfabetismo digital:

Se quisermos usar a internet, os jogos ou outros meios digitais para ensinar, precisamos equipar os alunos para compreendê-los e ter uma visão crítica desses meios: não podemos considerá-los simplesmente como meios neutros_de veicular informações e não devemos usá-los de um modo meramente funcional ou instrumental. Precisamos, nesse caso, é de uma concepção coerente e rigorosa de "alfabetização digital" - em outras palavras, do que as crianças precisam saber sobre esses meios. Isso é muito mais do que uma questão de knowhow ou de habilidades funcionais. As crianças precisam desenvolver uma capacidade crítica que lhes permita compreender como a informação é produzida, disseminada e consumida e como ela adquire significado.

Conforme o autor, se estamos num mundo rodeado de tecnologias e veículos midiáticos, e as crianças igualmente, elas precisam desenvolver um senso crítico. Precisamos oferecer condições para que as crianças não encarem as criações midiáticas como meios neutros, ao contrário, o público infantil precisa ter discernimento crítico e compreender que as informações veiculadas nos diversos meios de comunicação também têm um papel ideológico. Dessa maneira, os produtos midiáticos precisam ser consumidos pelas crianças a partir de uma leitura criteriosa, sob uma perspectiva crítica.

Nesse sentido, conforme Buckingham (2008, p. 4), necessitamos de uma forma de abordagem dos meios digitais que leve a questionamentos críticos para "desenvolver uma compreensão crítica das formas culturais e dos processos de comunicação", já que é necessário compreender que:

as tecnologias digitais são um fato inevitável da vida moderna. Os professores precisam usá-las de uma forma ou de outra - e o livro é uma tecnologia (ou um meio) tanto quanto a internet. Não podemos simplesmente abandonar a mídia e a tecnologia na educação e retornar a um tempo mais simples e natural. Os meios digitais, como a internet e os jogos de computador, realmente têm enorme potencial para o ensino, mas será difícil realizar esse potencial se persistirmos em considerá-los apenas como tecnologias, e não como formas de cultura e comunicação.

Diversos são os estudos sobre a mídia e uma das questões levantadas, e que precisamos nos atentar, é a respeito da ideia pré-concebida do poder das mídias de munir os cidadãos para participarem mais ativamente da vida pública:

é frequente encarar os novos media como portadores de um potencial considerável para a regeneração da participação democrática. A 
tecnologia digital, diz-se, pode "dar voz aos cidadãos", permitindo-lhes contribuir de forma positiva e autônoma nos debates públicos, e ter um papel mais activo no processo político (BUCKINGHAM, 2008, p. 10).

No entanto, não se tem essa eficácia comprovada (esse poder) e fica a dúvida sobre o alcance dos benefícios, isto é, corremos o risco de fugir desse "determinismo tecnológico" e cairmos em outra armadilha. Conforme Buckingham (2008, p. 10),

ao negar o determinismo tecnológico temos também que ter o cuidado de evitar o abismo a que Raymond Williams (1974) chamou "tecnologia determinada" - um raciocínio segundo o qual qualquer impacto que a tecnologia possa ter não passa de uma manifestação de outros processos sócio-econômicos.

Nesse sentido há que se ponderar e usar de cautela quando tratarmos do uso de tecnologias e, dessa forma, não tratá-las como meios isentos de influências subjetivas; há que se assumir uma postura questionadora. O que se coloca para ser entendido é que entre um "determinismo tecnológico" e uma "tecnologia determinada", vindo a tecnologia realmente fazer diferença, o que se deve, de acordo com Buckingham (2008, p. 10), é "explorar as condições sociais e institucionais pelas quais estas diferenças podem ser exercidas".

Dessa forma, precisamos considerar não somente o uso instrumental e funcional que os artefatos midiáticos apresentam, mas também sua atuação como formas de cultura e comunicação. Essas são questões que devem ser consideradas em estudos que envolvam mídias e tecnologia. Conforme aponta Buckingham (2008, p. 3), questões têm sido colocadas à margem das investigações a respeito das tecnologias, como a respeito da forma por meio da qual "as tecnologias medeiam e representam o mundo, como elas criam significado e como são produzidas".

Nesse sentido, a relação criança-mídia é vista por uma perspectiva crítica que considera a complexidade dessa relação, em que nenhuma das partes - texto, produção, público - se afirmam como determinantes na construção de significados. Considerar artefatos midiáticos como formas de cultura e comunicação abre caminhos para compreendermos melhor a forma de atuação destes na sociedade.

A revista é um dentre tantos outros produtos culturais que invadem a infância contemporânea; circula pelo cotidiano das crianças, fazendo parte do mundo vivenciado por elas. Pensar sua ação no mundo, como um artefato imbuído de cultura, é estabelecer uma rede de manifestações sociais significantes, o que possibilita lançar 
luzes sobre elementos que atuam no processo de construção das crianças sobre sua realidade/espaço.

Dentre as várias informações trazidas pelas revistas está a cartográfica. Temos a presença de produções cartográficas que mostram um jeito de entender o espaço. As revistas voltadas ao público infantil utilizam de técnicas e meios para atrair esse público, atingir suas especificidades e estabelecer um diálogo. Com isso mediam, em parte, a construção de significados da criança sobre o meio em que está inserida.

Como apontado por Buckingham (2008), precisamos considerar o uso instrumental e funcional desses artefatos, assim como suas atuações como forma de cultura e comunicação. Essa é uma questão que cabe aos que se ocupam da educação, refletir e pensar.

\section{Produções cartográficas presentes em revistas: reflexões e apontamentos para a educação}

As produções cartográficas são utilizadas pelas revistas como uma linguagem que auxilia na construção de textos, na expressão e comunicação de determinados assuntos. Assim, mediam formas de ver, compreender e agir sobre o espaço.

O conhecimento cartográfico, frente às mudanças da sociedade e especificamente às concepções de criança promovida pelos estudos de diferentes áreas, buscou estratégias para dialogar com esses sujeitos. Abandonou o velho paradigma da criança em devir, que está sempre em formação e preparação para serem agentes sociais e culturais na fase adulta. Isto é, a linguagem cartográfica também se adaptou aos anseios de uma sociedade contemporânea, que estabelece um novo lugar social para as crianças, seres que passaram a possuir fala e pensamentos atuando na construção da realidade que vivenciam.

Tais estratégias perpassaram por uma nova concepção da linguagem cartográfica, que buscou: compreender as crianças como atuantes na construção do mundo vivido, assumindo-as realmente como seres que pensam e formam opiniões frente às suas experiências; e direcionar uma atuação que não as coloque no papel de receptáculos do conhecimento construído pela humanidade até hoje, e sim como parte integrante e atuante da construção de conhecimento que não cessa em momento nenhum, sempre em movimento. 
Pensar em tais estratégias é um desafio que se coloca frente a uma sociedade que, geralmente, enxerga por meio do olhar do adulto. Na maioria das vezes, cabe a ele sempre pensar nas formas e maneiras de viver e fazer dentro do universo infantil. Ainda que não seja uma regra, devida as inúmeras mudanças que hoje colocam as crianças num patamar de agentes ativos, elas ainda, em menor escala do que no passado, são destituídas de responsabilidades frente à criação, ao aprendizado e ao conhecimento.

Nesse sentido, Lopes (2012) propõe que assumamos o termo "Cartografia Com Crianças" e não "Cartografia para Crianças", pois se fala em uma cartografia que parta do diálogo com esse sujeito. Isto é, uma cartografia que reconheça as especificidades da criança na forma de atuar e representar os espaços.

Callai (2005) discute a possibilidade e a importância de, nos anos iniciais do Ensino Fundamental, promover o ensino e aprendizagem da leitura de mundo e do espaço vivido como meio de exercício da cidadania. Nessa perspectiva, a Geografia enquanto disciplina escolar precisa ser entendida como parte essencial para o processo de ensino e aprendizagem da leitura e escrita, foco nessa etapa da escolarização. No entanto a leitura de mundo aqui referida não se restringe à leitura cartográfica:

Uma forma de fazer a leitura do mundo é por meio da leitura do espaço, o qual traz em si todas as marcas da vida dos homens. Desse modo, ler o mundo vai muito além da leitura cartográfica, cujas representações refletem as realidades territoriais, por vezes distorcidas por conta das projeções cartográficas adotadas. Fazer a leitura do mundo não é fazer uma leitura apenas do mapa, ou pelo mapa, embora ele seja muito importante. É fazer a leitura do mundo da vida, construído cotidianamente e que expressa tanto as nossas utopias, como os limites que nos são postos, sejam eles do âmbito da natureza, sejam do âmbito da sociedade (culturais, políticos, econômicos) (CALLAI, 2005, p. 228).

Lastória e Fernandes (2012) colocam que a criança dos anos iniciais do Ensino Fundamental, está apta à apropriação de diversas linguagens, e essa diversidade se faz também necessária para um ensino significativo que fale do mundo e que busque apreender sua complexidade. A importância da linguagem escrita e matemática é reconhecida tanto por professores quanto pelos responsáveis pelos alunos, no entanto a linguagem cartográfica fica relegada a segundo plano. Essa linguagem comumente tem sido interpretada num sentido mais restrito: 
A linguagem cartográfica é popularmente conhecida como a linguagem dos mapas, mas não se restringe apenas a eles. As plantas, os croquis, os gráficos, os globos terrestres, as anamorfoses (representações com formas alteradas), as fotografias aéreas e as imagens de satélite, são alguns exemplos de materiais que envolvem tal linguagem. Os mapas são, contudo, os mais usuais nas práticas escolares (LASTÓRIA; FERNANDES, 2012, p. 328).

Assim, precisamos partir da ideia da linguagem cartográfica como parte integrante do processo de aprendizagem de leitura e escrita das crianças nos anos iniciais do Ensino Fundamental. Essa linguagem diz respeito não apenas à leitura de mapas, mas também de outros materiais, como visto, o que leva a contribuições para o processo de ensino e aprendizagem que dialogue com o mundo que o aluno vivencia.

A cartografia participa da vida das crianças por meio de vários canais que povoam o imaginário infantil; assim participa da construção de mundos por meio de uma linguagem muito particular. Em um mapa, por exemplo, podemos ter desenhos, palavras, números etc. Esses atributos se apresentam a nós em um só lance de olhar, sendo preciso mobilizar vários campos do conhecimento para proceder à sua leitura e compreensão.

Essa linguagem humana exige um raciocínio que precisa ser aprendido, e a escola ficou incumbida dessa função. No cotidiano, tanto adultos quanto crianças se deparam com imagens cartográficas, seja quando evocadas devido a uma necessidade, sendo preciso empreender um esforço intelectual para sua compreensão e serventia, ou apenas surgindo sem que se tenha chamado a sua presença e passam por nós sem que nos detenhamos a analisar/pensar sobre elas.

A questão é que os mapas compõem o mundo que vivenciamos, fazem parte da edificação do social; são, pois, peças do quebra-cabeças social de experiências que passamos ao longo da vida. Daí, a necessidade de compreendermos sua linguagem, que é uma construção da humanidade e que participa na criação do mundo a que estamos integrados.

Pensando especificamente no contexto brasileiro, Cazetta (2009, s./p.) chama atenção para a forma como lidamos com mapas em nosso país, isto é, o modo como geralmente lidamos com essa linguagem:

A ausência de raciocínios cartográficos em nossas práticas espaciais e visuais cotidianas, característica de nosso contexto cultural 
brasileiro, sinaliza de algum modo uma tradição em se conceber a Cartografia como ramo do conhecimento que lida com mapas prontos e acabados, cujos detentores de seu arcabouço teórico-metodológico são, no momento atual, os engenheiros cartógrafos e/ou geógrafos especializados em cartografia ou sistemas de informação geográfica (SIG) ou Geographic Information System (GIS) - como alguns pesquisadores preferem.

Tendo isso em vista, nos parece, então, que a construção desse conhecimento ao longo do tempo encaminhou para uma ideia de mapa como objeto não passível de questionamentos. No entanto, estudos que afloraram a partir da década de 1980, colocaram esse objeto sob suspeita e hoje seu estatuto de verdade é questionado. Em outras palavras, a linguagem cartográfica passa por questionamentos no sentido de que não deve ser encarada como algo acabado, como detentora da verdade absoluta e com um sentido apenas.

Pressupondo-se que fazemos uso da linguagem para nos comunicarmos, como meio de expressão, podemos pensar também em o que seria uma linguagem cartográfica e suas convenções. Segundo Cazetta (2009, s./p.), é por meio de três dispositivos que a cartografia expressa no papel os espaços que deseja, a saber: a escala, a projeção e a simbologia. Temos ainda elementos que são considerados como linguagem "geográfica" por excelência, que segundo Cazetta (2009, s./p.) são: "os mapas, modelos tridimensionais (maquetes), imagens orbitais, fotografias aéreas verticais e mapeamentos".

Entretanto, pensar a linguagem cartográfica como meio para expressão de desejos, vontades, opiniões, pontos de vista distintos é um ensinamento que pode colaborar para o desenvolvimento de uma reflexão a respeito das imagens cartográficas com as quais nos deparamos em nosso dia-a-dia. Isto é, esses ensinamentos devem pendular entre considerar, questionar e refletir sobre a linguagem que se coloca a nós, levando-se em conta a sua dimensão.

Para além de comunicar e informar os mapas expressam valores, visões, escolhas que resultam do contexto social em que o produtor cartográfico se insere e que também atua na edificação desse contexto. Um mapa, ao ser visto, olhado, tem sua dimensão expressiva atuando na construção de mundos.

Nesse sentido, Oliveira (2012) põe em destaque a dimensão expressiva da linguagem cartográfica propondo que haja um deslocamento das dimensões 
comunicativa e informativa às quais a educação da linguagem cartográfica se habituou na escola. Segundo o autor, os mapas oficiais, versão do estado, com uma linguagem cartográfica convencional e padrão, parecem congelar nosso olhar sobre sua produção, criando-se um hábito pela repetição. Dessa forma, nosso olhar se detém sobre essas produções não conseguindo ir além, ficam em destaque suas dimensões comunicativa e informativa. Tendo isso em vista, a proposta de Oliveira (2012, p. 44), em suma, é que os mapas, no contexto escolar, vão além de informar e comunicar apenas, mas, essa perspectiva não deve

\begin{abstract}
ser eliminada dos percursos escolares. Muito pelo contrário, ela deve permanecer como um dos percursos traçados pelos mapas nos currículos e na cultura, mas ela deve também ser colocada em intensa tensão, desfigurada, fraturada, esmaecida, nas obras que também tenham - sobretudo tenham - caráter expressivo, ou seja, possuam alguma força de mobilização do pensamento que se coloque aquém e além da informação, da comunicação, que faça convergir para si alguma potência de dizer o ainda não dito, que crie em torno de si um campo de forças que nos leve a pensar algo a partir de sensações que não sejam somente pensamentos racionalizáveis, mas também sensações sem sentido que nos levem a deslocar alguma coisa de seu lugar habitual, ou seja, que nos exija pensar, nem que seja pensar que a cartografia não é uma linguagem que somente comunica, mas também e sobretudo expressa visões de mundo, configurações e imaginações espaciais.
\end{abstract}

A subjetividade é inerente ao processo de criação daquele que produz imagens que evocam territórios e daqueles que fazem uso dessas imagens. Portanto, tanto quem cria como quem usa imagens cartográficas participa na criação de mundos. Tendo isso em vista, precisamos direcionar um olhar crítico para as produções cartográficas que encontramos em artefatos midiáticos, o que conduz para a promoção de uma educação questionadora, de forma a implicar diretamente na construção de significados sobre o mundo vivenciado.

\title{
Conclusão
}

Extrapolando os muros da escola, as crianças também se deslocam por outros lugares e interagem com outros objetos que se relacionam com realidade e espaço, mas que não são estritamente materiais didáticos voltados para a cartografia. No contexto de uma sociedade capitalista, em que a criança se constitui em mercado consumidor, muitos são os produtos midiáticos direcionados ao público infantil. Nesses produtos temos presente a cartografia enquanto linguagem, com sua 
dimensão expressiva em ação. Compreender como e quais relações se estabelecem entre as produções cartográficas trazidas por artefatos midiáticos e a infância conduz à formação de um olhar crítico e aponta para os limites e possibilidades de atuação da educação na construção da realidade vivenciada.

\section{REFERÊNCIAS}

BUCKINGHAM, David. Precisamos realmente de educação para os meios? Comunicação \& Educação, Ano XVII, n. 2, p. 41-60, jul./dez. 2012. Disponível em:< http://www.revistas. usp.br/comueduc/article/view/73536/77235>. Acesso em: 15 nov. 2015.

Repensando a criança consumidora: novas práticas, novos paradigmas. Comunicação Mídia e Consumo, São Paulo, v. 09, n. 25, p. 42-72, ago. 2012. Disponível em: <http://revistacmc.espm.br/index.php/revistacmc/article/view/311/pdf 2>. Acesso em: 20 out. 2015.

. Aprendizagem e Cultura Digital. Revista Pátio, Editora Artmed. n. 44, jan. 2008. Disponível em: <http://www.cereja.org.br/arquivos upload/david buckingham aprendizagem cultura digital.pdf>. Acesso em: 10 out. 2015.

CALLAI, Helena Copetti. Aprendendo a ler o mundo: A geografia nos anos iniciais do ensino fundamental. Cadernos Cedes, Campinas, vol. 25, n. 66, p. 227-247, maio/ago. 2005. Disponível em: Disponível em http://www.cedes.unicamp.br. Acesso em: 05 out. 2015.

CAZETTA, Valéria. Aproximações e distanciamentos entre a linguagem cartográfica e outras linguagens. Biblio $3 W$. Revista Bibliográfica de Geografía y Ciencias Sociales. Universidad de Barcelona. v. 14, n. 847, novembro, 2009. Disponível em: <http://www.ub.es/ geocrit/b3w-847.htm>. Acesso em: 05 out. 2015.

LASTORIA, A. C.; FERNANDES, S.A.S. A Geografia e a linguagem cartográfica: de nada adianta saber ler um mapa se não se sabe aonde quer chegar. Ensino em Revista. v. 19, n. 2, p. 323-334, jul/dez. 2012.

LOPES, Jader Janer Moreira. Mapa dos cheiros: cartografia com crianças pequenas. Revista Geografares, n.12, p. 211-227, julho, 2012.

LOPES, Jader Janer Moreira. Geografia da Infância: contribuições aos estudos das crianças e suas infâncias. Revista de Educação Publica, Cuiabá, v. 22, n.49/1, p. 
283-294, maio/ago., 2013. Disponível em: http://periodicoscientificos.ufmt.br/index. php/educacaopublica/arti cle/view/915/716. Acesso em: 10 out. 2015.

OLIVEIRA JR., Wencesláo Machado de. Mapas em deriva - imaginação e cartografia escolar. Geografares, Vitória (ES), v. 12, p. 1-49, jul., 2012.< http://www.periodicos.ufes.br/geografares/ article/viewFile/3187/2397 >. Acesso em: 10 out. 2015. 